\title{
Carbon Monoxide Generation in Fires: Effect of Temperature on Halogenated and Aromatic Fuels
}

\author{
KATARZYNA KACZOREK, ANNA A. STEC, and T. RICHARD HULL \\ Centre for Fire and Hazard Science \\ University of Central Lancashire \\ Preston, Lancashire, PR1 2HE, UK
}

\begin{abstract}
Carbon monoxide is widely regarded as the major toxicant in fire effluents. It is produced as a result of incomplete combustion, by low temperatures, flame quenching, or under-ventilation. Polymers containing halogens and aromatic rings give higher carbon monoxide yields in well-ventilated conditions, when burnt in the steady state tube furnace (ISO 19700) at a furnace temperature of $650{ }^{\circ} \mathrm{C}$. This is believed to result from flame quenching by hydrogen halides or the enhanced stability of aromatic rings in flames, respectively. This work investigates the effect of ventilation condition and furnace temperature on the yield of carbon monoxide from burning mixtures of polyvinyl chloride and polyethylene, polyamide 6 containing a brominated flame retardant and an antimony synergist, and polystyrene. In each case, the high carbon monoxide yields in well-ventilated burning reduced at higher furnace temperatures, showing a diminution of fire toxicity above $850^{\circ} \mathrm{C}$.
\end{abstract}

KEYWORDS: carbon monoxide, toxicity, halogen, aromatic, steady state tube furnace.

\section{INTRODUCTION}

UK statistics indicate that most people die in fires due to inhalation of smoke and toxic gases [1]. Injuries from smoke and toxic fumes have increased continuously from an annual rate of approximately 1000 to more than 6000 from the mid-1970s to 2000. This is related to modern materials, and the changes in living styles over the period, which have led to more upholstered furnishings being used in the average British home, and, therefore, a greater fire load [2].

Fire smoke toxicity has assumed a greater importance in high risk applications. The major factor in the assessment of fire hazard is an estimation of yields of toxic products from fires [3]. In a fire, thermal decomposition of solid material generates buoyant gaseous fuel vapours, which can burn above the solid material. Chemical processes are responsible for the generation of flammable volatiles, while physical changes result in melting and charring [4].

The various physical processes that occur during thermal decomposition depend on the nature of the material. For example, as thermosetting polymeric materials are cross-linked and therefore infusible and insoluble, simple phase changes upon heating are not possible. Thermoplastics, such as polyvinyl chloride (PVC), polystyrene (PS), polyamide 6 (PA6) and low density polyethylene (LDPE), can be softened by heating without irreversible changes to the material, provided heating does not exceed the minimum thermal decomposition temperature.

The pyrolysis of a polymer involves decomposition, turning chains of 10,000-100,000 carbon atoms into species small enough to be volatilised. In some cases, the chain releases groups most easily from its ends, known as end-chain scission or unzipping (e.g. PMMA). In many more cases, the chain breaks at random points along its length, known as random chain scission. A third process, where stable molecules, attached to the backbone as side chains, are lost, is known as chain stripping. The resulting chain may undergo scission to volatiles or lose further substituents forming double bonds which cross-link and undergo carbonisation, ultimately leading to char formation. Thus, the conversion of an organic polymer to volatile organic molecules may follow four general mechanisms. While some polymers fall exclusively into one category, others exhibit mixed behaviour [5]. LDPE, PA6 and PS all undergo predominantly random chain scission, leading to oligomeric fragments and cyclised hydrocarbons (LDPE), a mixture of dehydrated monomers and their decomposition products (PA6), and a mixture of monomer, dimer and trimer (PS). $\mathrm{PVC}$ is an example of a polymer producing both volatiles and char when decomposed or combusted. At elevated temperatures, PVC undergoes a dehydrochlorination reaction to release hydrogen chloride $(\mathrm{HCl})$ and forms a conjugated polyene [6], which undergoes further rearrangements and product elimination at 
higher temperatures to produce a complex mixture of hydrocarbons with aromatic materials predominating (Fig. 1). At temperatures between $200-300{ }^{\circ} \mathrm{C}, 80-95 \%$ of the chlorine content of rigid (or unplasticised) $\mathrm{PVC}$ is released as $\mathrm{HCl}, 70 \%$ within one minute at $300^{\circ} \mathrm{C}$ [7]. Under combustion conditions at $650{ }^{\circ} \mathrm{C}, 75-$ $90 \%$ of chlorine has been recovered as $\mathrm{HCl}[8]$. In some formulations, some chlorine may remain in the residue. For example calcium carbonate, a common filler in $\mathrm{PVC}$, will react with $\mathrm{HCl}$ to produce nonvolatile calcium chloride, while releasing non-fuel carbon dioxide $\left(\mathrm{CO}_{2}\right)$. In practice the chorine content of the residue has been found to depend to some extent on the decomposition conditions. When a plasticised PVC containing calcium carbonate was decomposed under non-flaming conditions, $58 \%$ of chlorine was released as $\mathrm{HCl}$. Under combustion conditions at $650{ }^{\circ} \mathrm{C}$, the recovery decreased to $34 \%$, but at $1000{ }^{\circ} \mathrm{C}$ calcium carbonate decomposes to calcium oxide and gas phase chloride recovery increased to $43 \%$ [9].<smiles>CCC(Cl)CC(Cl)CC(Cl)CC(Cl)CC(Cl)CC(Cl)CC(Cl)CC(Cl)CC(Cl)CC(Cl)CC(C)Cl</smiles><smiles>CC=CC=CC=CC=CC=CC=CC=CC=CC=CC=CC=CC</smiles><smiles>c1ccccc1</smiles><smiles>C#C</smiles>

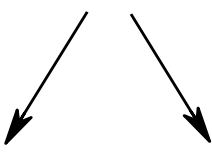<smiles>c1ccc2ccccc2c1</smiles>

Volatilisation of unsaturated and aromtic molecules

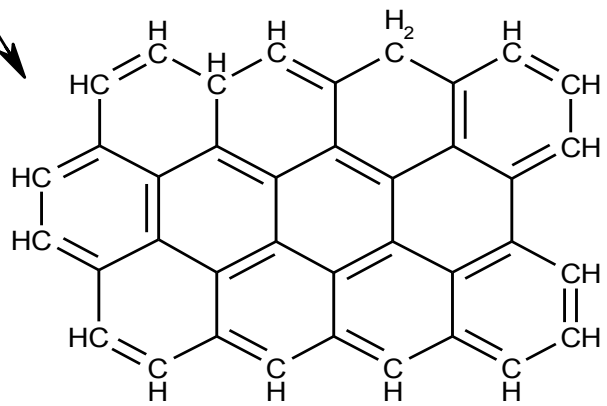

Idealised Char formation

Fig. 1. PVC decomposition [5].

PVC burns with a low heat release rate, because $\sim 60 \%$ of its mass is released as $\mathrm{HCl}$, which then inhibits the conversion of carbon monoxide $(\mathrm{CO})$ to $\mathrm{CO}_{2}$. This is the major heat release step in polymer combustion. When hydrogen chloride gas comes off on heating, a double bond forms between alternate carbons, strengthening the chain in the solid residue. As this residue gets hotter, the chain either cross-links as double bonds open and attachment to neighbouring chains occur, eventually leading to char formation, or they break down and cyclise to form volatile aromatic hydrocarbons. If these only contain a few rings, they will produce lots of black smoke, and if they are large or cross-linked, the residue may form a stable protective char layer [10].

A typical unwanted fire may progress through several stages which may include: non-flaming/smouldering combustion, well-ventilated flaming to under-ventilated flaming [11-12]. The ventilation of flaming fires can be characterized in terms of the equivalence ratio, $\phi$ (Eq. 1).

$\phi=\frac{\text { actual fuel }- \text { to }- \text { air ratio }}{\text { stoichiometric fuel }- \text { to }- \text { air ratio }}$ 
Well-ventilated flaming fires occur when there is plenty of air available so that the ratio of fuel-to-air is low. Under these conditions, combustion is most efficient, so that, for most materials, the main products are carbon dioxide, water and heat - initially the yields of smoke and toxic products tend to be low. The toxic potency and toxic hazards from simple CHO polymers are therefore also low in well-ventilated flaming, but the fire is likely to grow quickly, producing considerable quantities of heat and carbon dioxide while consuming oxygen [12-15]. As the fire grows, the temperature rises, the volume of effluent increases, and the oxygen becomes depleted from the surrounding atmosphere.

Ventilation-controlled flaming fires occur when the air supply is restricted compared to the fuel available for combustion. They may consist of pre-flashover fires in enclosed spaces or large post-flashover fires, where all surfaces are ignited in high temperature (often as high as $1000^{\circ} \mathrm{C}$ ) conflagrations in very large or ventilated spaces. Ventilation-controlled fires tend to be the worst case for toxicity, because they produce large amount of effluent, containing high yields of toxic products, for instance: $\mathrm{CO}, \mathrm{CO}_{2}, \mathrm{HCN}$, organic products, smoke, and inorganic acid gases [12].

Carbon monoxide is always present to some extent in all fires, irrespective of the materials involved or the stage (or type) of fire, so that there is almost always some degree of risk of asphyxia from CO exposure [14]. As the most toxicologically significant fire gas, and as an indicator of fire condition, the range of conditions favouring the formation of $\mathrm{CO}$ must be considered. $\mathrm{CO}$ results from incomplete combustion, which can arise from:

- Insufficient heat (e.g. during smouldering) [15].

- Quenching of the flame reactions (e.g. when halogens are present in the flame, or excessive ventilation cools the flame) [16].

- The presence of stable molecules, such as aromatics which survive longer in the flame zone, giving high $\mathrm{CO}$ yields in well-ventilated conditions, but lower than expected yields in underventilated conditions [17].

- Insufficient oxygen (e.g. in underventilated fires, large radiant heat fluxes pyrolyse the fuel even though there is not enough oxygen to complete the reaction) [11].

The current study is focused on the transition from well-ventilated flaming (lower temperatures and adequate oxygen supplies) to fully-developed flaming (higher temperatures and inadequate oxygen).

\section{Mode of Action of Halogens as Flame Retardants}

Both the $\mathrm{HCl}$ evolved from the decomposition of $\mathrm{PVC}$, and the $\mathrm{HCl}$ or $\mathrm{HBr}$ evolved from the decomposition of halogenated flame retardants will interfere with the gas phase combustion process.

Flaming combustion involves a very small number of highly reactive free radicals to propagate the rapid gas phase oxidation processes. For ignition to occur, the number of radicals must increase. This occurs in Eqs. 2 and 3 where each · represents an unpaired electron.

$\mathrm{H} \cdot+\mathrm{O}_{2} \rightarrow \mathrm{OH} \cdot+\cdot \mathbf{O} \cdot$

$\cdot \mathrm{O} \cdot+\mathrm{H}_{2} \rightarrow \mathrm{OH} \cdot+\mathrm{H} \cdot$

Halogen-containing flame retardants act by interfering with the radical chain mechanism taking place in the gas phase. The high-energy $\mathrm{OH} \cdot$ and $\mathrm{H} \cdot$ radicals formed by chain branching are removed by the halogencontaining flame retardant (RX). At first the flame retardant breaks down to

$\mathbf{R X} \rightarrow \mathbf{R} \cdot+\mathbf{X} \cdot$

where $\mathrm{X} \cdot$ is either $\mathrm{Cl} \cdot$ or $\mathrm{Br} \cdot$. The halogen radical reacts with a fuel molecule to form the hydrogen halide:

$\mathbf{X} \cdot+\mathbf{R H} \rightarrow \mathbf{R} \cdot+\mathbf{H X}$ 
which in turn interferes with the radical chain mechanism:

$\mathbf{H X}+\mathbf{H} \cdot \rightarrow \mathbf{H}_{2}+\mathbf{X} \cdot$

The removal of $\mathrm{H}$. is key to the elimination of the main chain branching step (Eq. 2) (when 1 unpaired electron becomes 3 ).

$\mathrm{HX}+\mathrm{OH} \cdot \rightarrow \mathrm{H}_{2} \mathrm{O}+\mathrm{X} \cdot$

The removal of $\mathrm{OH}$. blocks the main heat release step of hydrocarbon combustion, the conversion of $\mathrm{CO}$ to $\mathrm{CO}_{2}$, by replacement with less reactive halogen free radicals in the gas phase [18]. The $\mathrm{H} \cdot$ and $\mathrm{OH} \cdot$ radicals are essential for many flame reactions and are involved in the main heat release step in Eq. 8.

$\mathrm{CO}+\mathrm{OH} \cdot \rightarrow \mathrm{CO}_{2}+\mathrm{H}^{\cdot}$

Thus loss of $\mathrm{H} \cdot$ and $\mathrm{OH} \cdot$ will reduce the $\mathrm{CO}_{2} / \mathrm{CO}$ ratio.

The high-energy $\mathrm{H}$ - and $\mathrm{OH}$ - radicals are removed by reaction with $\mathrm{HX}$ and replaced with lower-energy Xradicals. The actual flame retardant effect is thus produced by HX.

The hydrogen halide consumed in this way is regenerated by reaction with a hydrocarbon:

$$
\mathbf{X} \cdot+\mathbf{R H} \rightarrow \mathbf{R} \cdot+\mathbf{H X}
$$

Thus HX could be considered to act as a catalyst.

Meanwhile, in the condensed phase, having lost HX, the resulting unsaturated polyenes may act as char precursors, forming products with a tendency to cyclize and condense to yield carbonaceous products, which protect the condensed phase below the flame zone against attack by oxygen and radiant heat. In PVC, containing $\sim 60 \%$ chlorine, char formation is a significant fire retardant mechanism.

In the presence of antimony oxide $\left(\mathrm{Sb}_{2} \mathrm{O}_{3}\right)$, the efficiency of halogenated flame retardants is improved, although $\mathrm{Sb}_{2} \mathrm{O}_{3}$ has no flame retardant effect on its own. This is believed to result from the formation of volatile $\mathrm{SbX}_{3}$ and other species which are more effective halogen carriers than $\mathrm{HX}$.

The yield of combustion species has been shown to depend on the material and on the ventilation and temperature conditions $[8,12]$. For example for a particular material the $\mathrm{CO}$ yield correlates with fire conditions. 


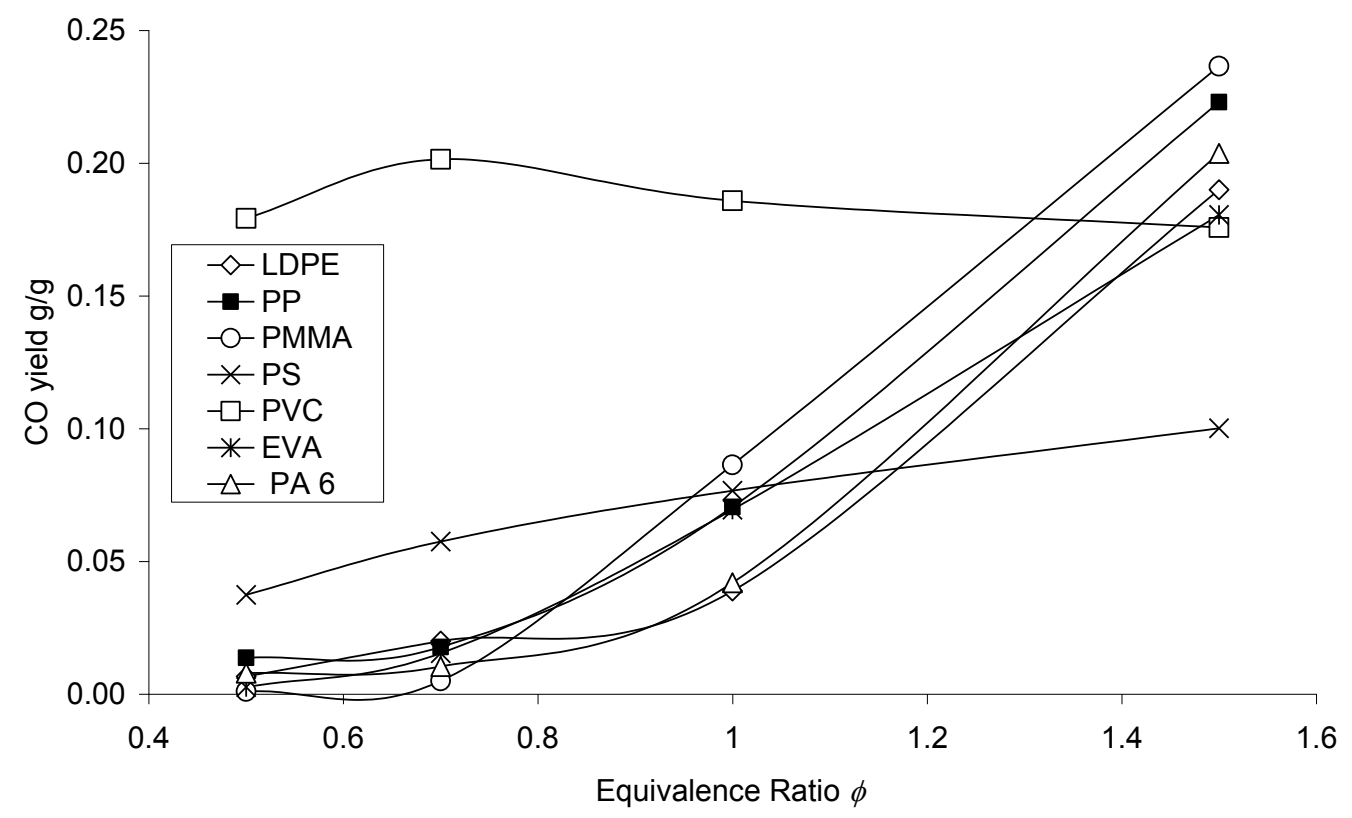

Fig. $2 \mathrm{CO}$ yields from various polymers as a function of equivalence ratio at a furnace temperature of $650{ }^{\circ} \mathrm{C}$.

Figure 2 shows the carbon monoxide yield from various polymers as a function of ventilation condition, generated in the steady state tube furnace $[16,19,20]$. For most polymers there is a very small CO yield in well-ventilated conditions $(0.5<\phi<0.7)$, increasing progressively with under-ventilation to give large yields when $\phi>1.0$. Two exceptions to this behaviour are apparent in Fig. 2: PS, which contains a stable aromatic structure, giving incomplete combustion in well-ventilated conditions with a higher $\mathrm{CO}$ yield, but a lower CO yield in under-ventilated conditions, as the aromatic ring fails to decompose; PVC, which shows a consistently high $\mathrm{CO}$ yield, due to the trapping of $\mathrm{H}$ - and $\mathrm{OH}$ - radicals by $\mathrm{HCl}$, blocking the conversion of $\mathrm{CO}$ to $\mathrm{CO}_{2}$.

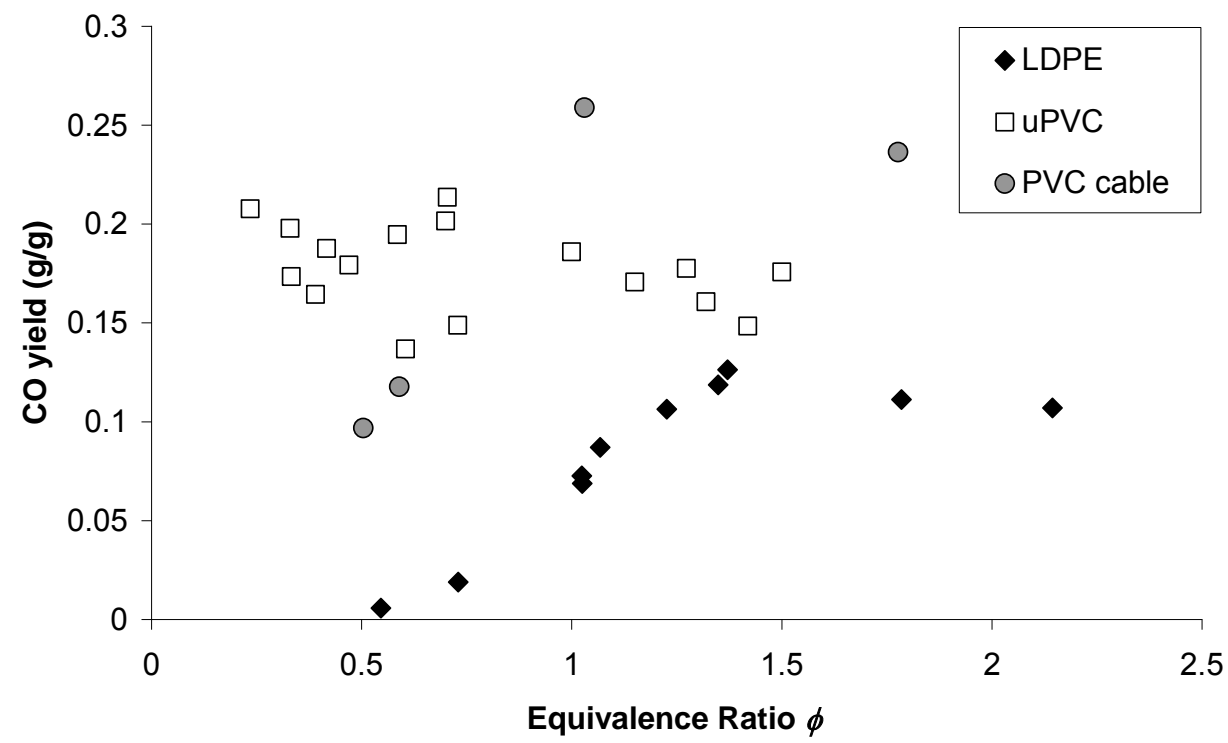

Fig. 3. Variation of CO yield for LDPE, unplasticised PVC, and PVC cable containing plasticizer and chalk.

This effect is even more noticeable in commercial products such as plasticised PVC covered electric cable, where the PVC is compounded with equal masses of hydrocarbon based plasticiser and chalk (Fig. 3). This suggests that the $\mathrm{HCl}$ inhibits the $\mathrm{CO}$ oxidation resulting in similar $\mathrm{CO}$ yields, even when the PVC content 
had been reduced by a factor of 3 [10]. Surprisingly, the CO yields for the cable, which is only 33\% PVC, are higher than for unplasticised PVC.

\section{EXPERIMENTAL}

To show the effect of material formulation and fire conditions on the toxic product yield and the predicted combustion toxicity, experimental data is presented from the steady state tube furnace [21]. This is one of the only techniques capable of recreating a steady state for all fire conditions including those replicating under-ventilated combustion. The apparatus may be set up to burn material at a particular equivalence ratio, from well-ventilated through to forcing a steady state under the most toxic oxygen-depleted conditions. It does so by feeding the sample and air into a tube furnace at fixed rates, so that the flame front is held stationary relative to the furnace. This enables it to provide reliable data on the product yields as a function of equivalence ratio. Unlike a 'flammability test' where a material's chemistry dictates the rate of burning, in the steady state tube furnace all materials are burned at a fixed rate.

The apparatus has been described in detail elsewhere [17]. Samples are fed into the furnace in a silica boat travelling at $\sim 35 \mathrm{~mm} \cdot \mathrm{min}^{-1}$. By varying the primary air flow, different fire conditions were created at known equivalence ratios. Oxygen depletion and yields of carbon dioxide, carbon monoxide and smoke may be determined for each fire condition, as previously reported [22].

Samples for the measurement of oxygen, carbon dioxide and toxic gases are taken continuously from the mixing chamber. These gas streams are passed through a drying agent and smoke filtration system and the gas concentrations are measured using electrochemical cells, paramagnetic analysers $\left(\mathrm{O}_{2}\right)$ and nondispersive infrared (NDIR) sensors.

The steady state tube furnace (SSTF) method has been found suitable for generating fire effluents for the quantification of toxic combustion products, with particular emphasis on its use as an engineering tool for quantifying the yield of toxic products under a range of fire conditions, characterised by temperature and the equivalence ratio [23]. It has been recognised as one of the only devices with such a capability by ISO, as ISO/TS 19700 [24].

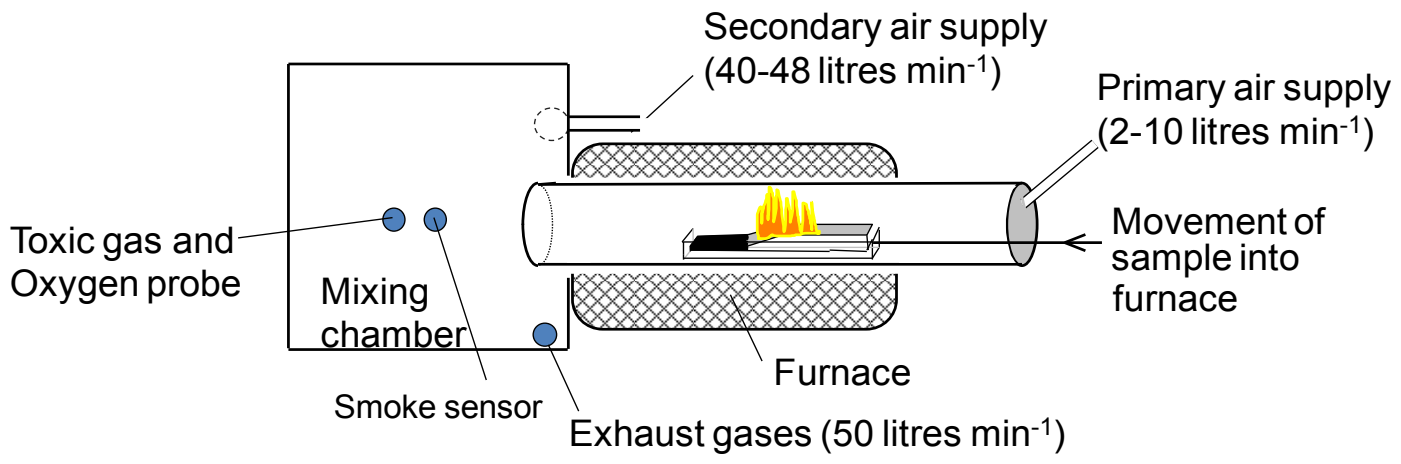

Fig. 4. Steady state tube furnace apparatus ISO TS 19700 schematic.

This method was designed to replicate real fire conditions, and in any such physical fire model it is essential to ensure that those conditions are being met [24]. By using a range of different temperatures and air flows it is possible to reproduce all the different fire stages and types, including low-temperature nonflaming oxidative decomposition, well-ventilated flaming $(\phi<0.75)$ and high-temperature under-ventilated (post-flashover) flaming decomposition conditions $(\phi>2)$ [24].

The aim of the current work was to investigate the effect of temperature, and presence of halogens or aromatic species on the carbon monoxide yields.

\section{Materials}

All unadulterated polymers were used in the form of commercial pellets: low density polyethylene (LDPE) (Cleaflex, Polimeri Europa), polyvinyl chloride (PVC) (Doeflex-Vitapol), polystyrene (PS) (GPPS 1540) 
Atofina. In addition, granulated glass fibre reinforced PA6, containing brominated flame retardant and antimony oxide synergist containing $44 \%$ polyamide 66 (Ultramid A27), $30 \%$ glass fibres (Vetrotex EC 10 983), $20 \%$ bromopolystyrene (BrPS) (Saytex HP 3010G), and $6 \%$ antimony trioxide $\left(\mathrm{Sb}_{2} \mathrm{O}_{3}\right)(\mathrm{as}$ masterbatch in PA 6 Campine 2617).

\section{RESULTS AND DISCUSSION}

\section{Mixtures of LDPE and PVC Pellets}

In order to investigate the interaction of hydrogen chloride on the oxidation of carbon monoxide, a mixture of PVC and LDPE pellets containing equal masses of each polymer was burnt at different furnace temperatures in the steady state tube furnace. The carbon monoxide yields were determined, and are reported as a function of equivalence ratio for each temperature in Fig. 5. For comparison, average values from the data in Fig. 3 have been used to calculate the yield of $\mathrm{CO}$ at $650{ }^{\circ} \mathrm{C}$, if the same equal masses of LDPE and PVC had been burned separately. This suggests that the $\mathrm{HCl}$ from the PVC also inhibits the conversion of $\mathrm{CO}$ to $\mathrm{CO}_{2}$ from the LDPE, as might be expected.

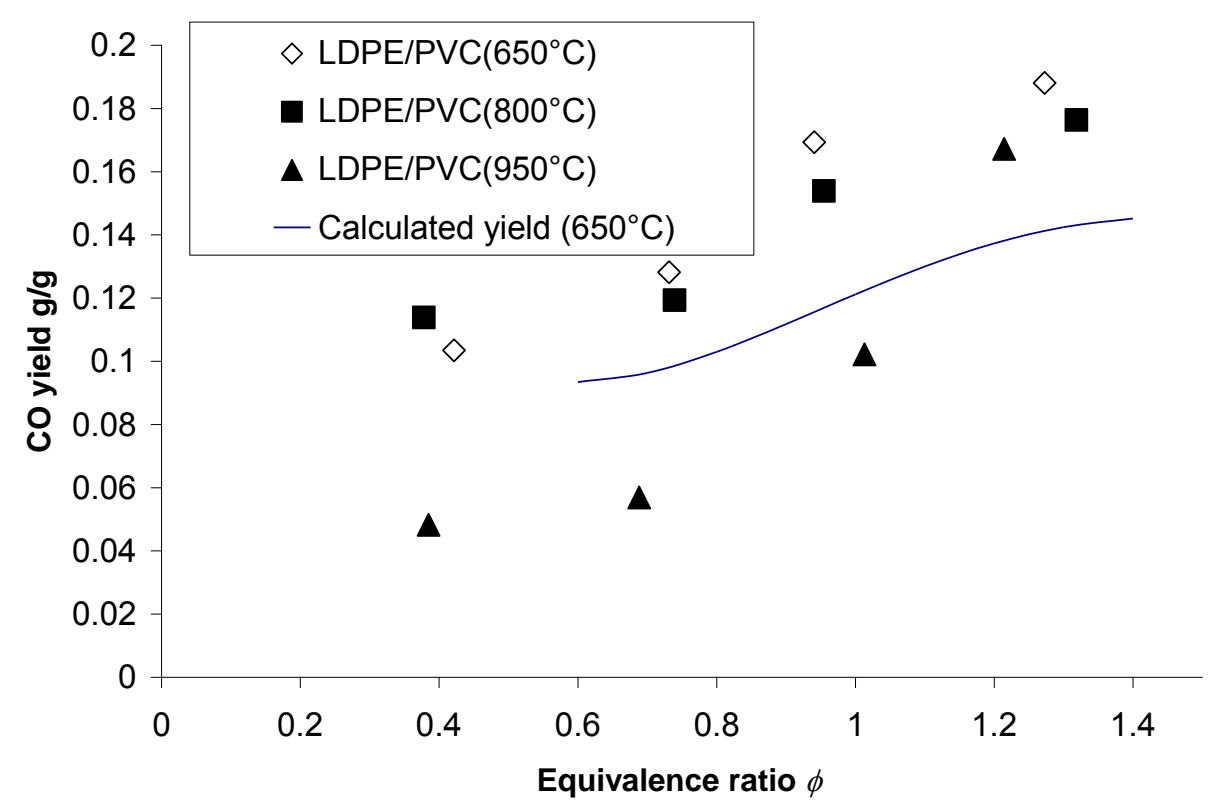

Fig. 5. CO yield of LDPE/PVC mixture at 650,800 and $950{ }^{\circ} \mathrm{C}$ and the yield calculated from the yields of the LDPE and PVC burnt separately, from data in Fig. 3.

At lower temperatures in well-ventilated conditions, conversion of $\mathrm{CO}$ to $\mathrm{CO}_{2}$ is inhibited. While $\mathrm{HCl}$ inhibits the conversion of $\mathrm{CO}$ to $\mathrm{CO}_{2}$ from PVC/LDPE at 650 and $800{ }^{\circ} \mathrm{C}$, at $950{ }^{\circ} \mathrm{C}$ the conversion of $\mathrm{CO}$ to $\mathrm{CO}_{2}$ is fairly efficient. Therefore, the higher toxicity of PVC from $\mathrm{CO}$ diminishes at higher temperatures.

\section{PA6 with Brominated Polystyrene and Antimony Trioxide}

Glass reinforced polyamide 6 containing brominated polystyrene and antimony oxide, in a typical industry formulation, was investigated to see if the same temperature dependent carbon monoxide oxidation inhibition effect was observed. The sample contained $30 \%$ glass fibre, and as the results are reported on a mass charge basis, the carbon monoxide yields would be $30 \%$ lower than they would have been if material did not contain glass fibre filler. Fig. 6 shows strong inhibition of the conversion of $\mathrm{CO}$ to $\mathrm{CO}_{2}$ at $650{ }^{\circ} \mathrm{C}$ and $825^{\circ} \mathrm{C}$, but almost no inhibition in well-ventilated conditions at $950{ }^{\circ} \mathrm{C}$.

Some related work has been published on the efficiency of halocarbon flame extinguishing agents $\mathrm{CF}_{3} \mathrm{Br}$ in methane air flames as a function of temperature [25]. This showed that the efficiency was optimised at lower temperatures, and this was attributed to longer residence times in the flame zone. In these 
experiments enhanced efficiency was observed in counterflow flames, believed to increase the regeneration of $\mathrm{Br} \cdot$ from $\mathrm{HBr}$. In a further investigation [26] it was found that the presence of water vapour (ubiquitous in polymer flames) diminished the effectiveness of the flame inhibition by $\mathrm{CF}_{3} \mathrm{Br}$. Elevated temperatures $\left(\sim 900{ }^{\circ} \mathrm{C}\right)$ will favour greater dissociation, but also higher diffusion rates. Thus, while there will be a greater concentration of $\mathrm{H}$. and $\mathrm{OH}$. radicals from Eqs. 2 and 3, the X. concentration in the flame will be lower, and the recombination reaction, Eq. 9, is likely to be slower.

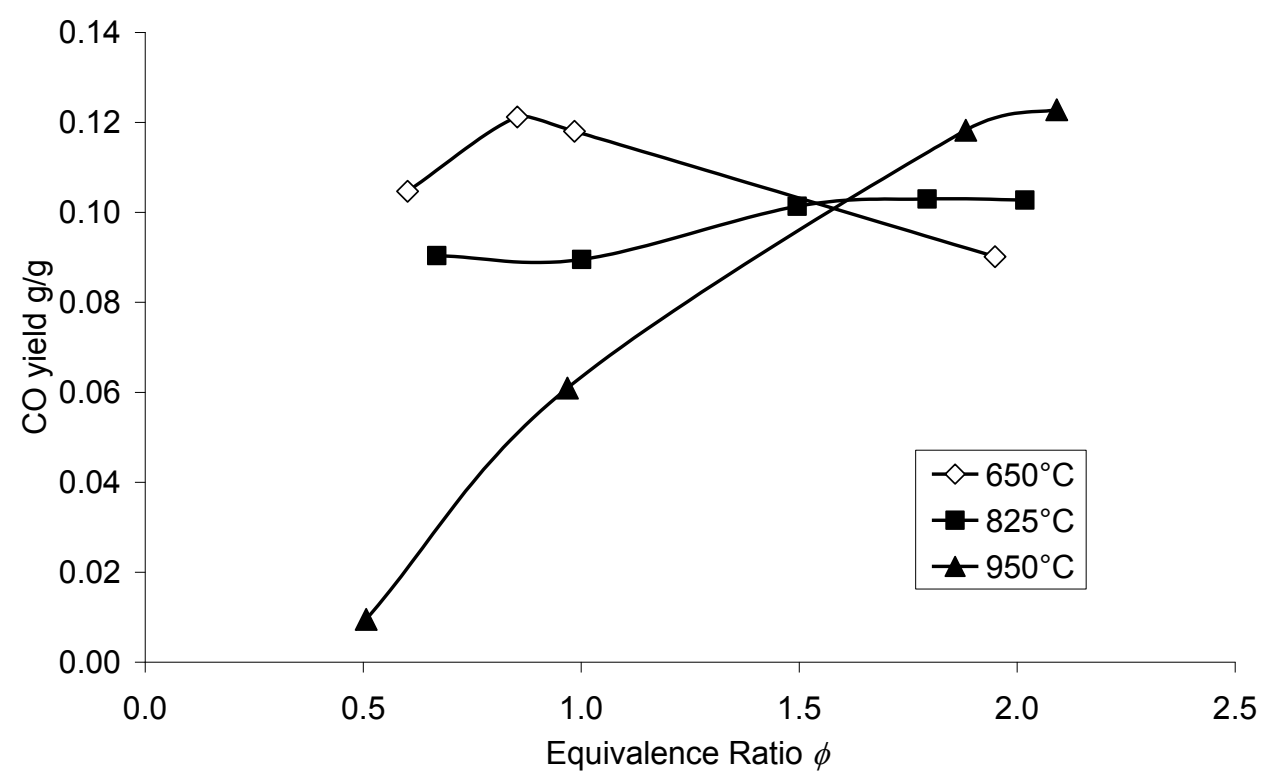

Fig. 6. Variation of $\mathrm{CO}$ yield with temperature and equivalence ratio for glass fibre reinforced PA6 containing brominated flame retardant and antimony oxide.

\section{Polystyrene}

Finally, the enhanced stability conferred by aromatic structures (whether from polymers which already contained aromatic groups such as PS, or from polymers which decompose to form gas phase aromatic fuels, such as PVC) was investigated as a function of temperature. As shown in Fig. 2, polystyrene shows high $\mathrm{CO}$ yields in well-ventilated combustion, but lower than expected $\mathrm{CO}$ yields in under-ventilated combustion, at a furnace temperature of $650{ }^{\circ} \mathrm{C}$. Figure 7 shows the variation of carbon monoxide yield as a function of temperature and equivalence ratio. At 750 and $850{ }^{\circ} \mathrm{C}$ the $\mathrm{CO}$ yield drops from the elevated level of $0.04 \mathrm{~g} / \mathrm{g}$ to a very low level, around $0.005 \mathrm{~g} / \mathrm{g}$. While this increases as a function of equivalence ratio, under the conditions reported here, all the carbon monoxide yields in under-ventilated conditions are lower than those typical of other hydrocarbon polymers. 


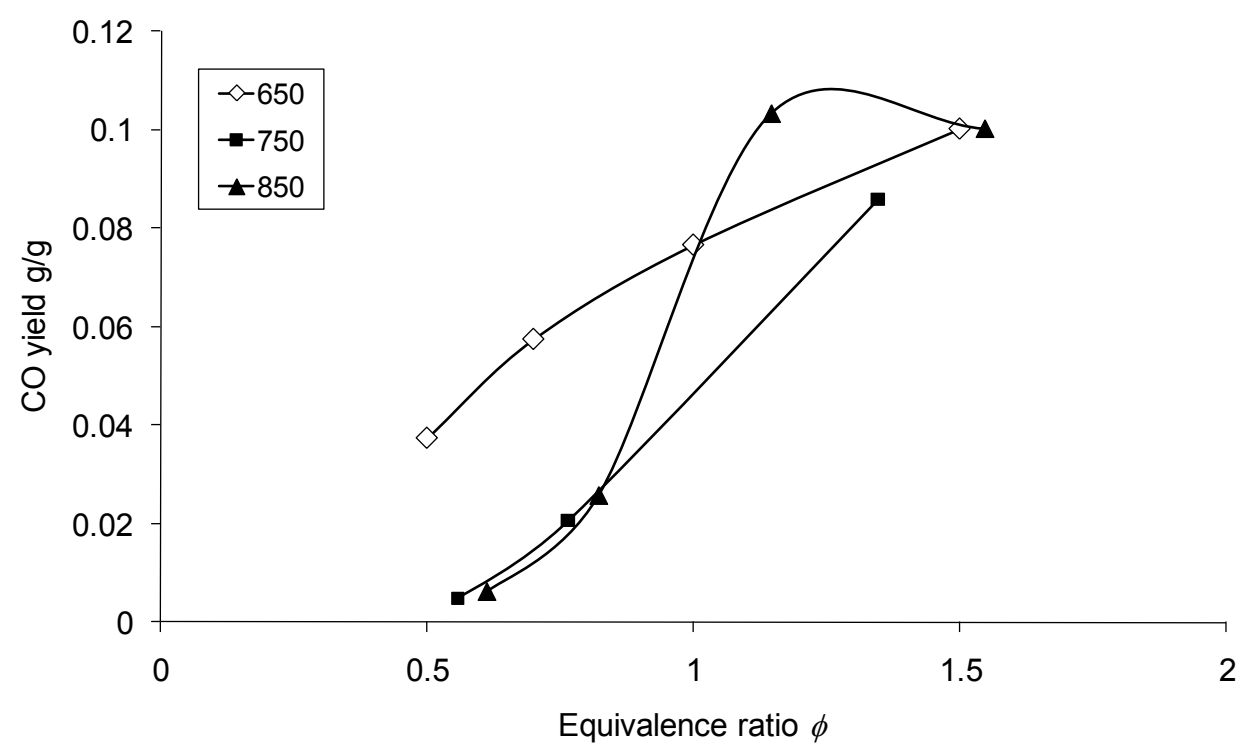

Fig. 7. Variation of $\mathrm{CO}$ yield with temperature and equivalence ratio for polystyrene.

\section{CONCLUSIONS}

Toxic gases have been identified as major factors in fire deaths all over the world. The large amounts of synthetic polymer materials in common use increases the importance of fire toxicity. $\mathrm{CO}$ and hydrocarbon yields can be used as an indicator of the fire ventilation condition. Under well-ventilated conditions, combustion is most efficient, so that for most materials, the main products are carbon dioxide, water, and heat, and the $\mathrm{CO}$ and hydrocarbons yields tend to be low. Under-ventilated fires tend to be the worst case for toxicity, because they produce large amount of effluent containing high yields of toxic products, such as $\mathrm{CO}$ and hydrocarbons. In addition, when temperatures are greater, this can have a dramatic effect on both the fire toxicity and the flame inhibition as this work shows.

The equivalence ratio is a very useful parameter for characterisation of fire conditions. It shows that for most materials, there is a low yield of carbon monoxide under well-ventilated $(\phi<0.7)$ conditions, and a high yield in under-ventilated conditions $(\phi>1.5)$. The anomalous flame inhibition behaviour of PVC and PS observed at $650{ }^{\circ} \mathrm{C}$ becomes less apparent as the temperature increases. A comparison of carbon monoxide yields for the LDPE and PVC pellet mixture with pure LDPE and pure PVC materials as pellets as a function of equivalence ratio showed that the co-burning of the two fuels led to greater inhibition of $\mathrm{CO}$ oxidation per gram of $\mathrm{HCl}$ volatilised than for PVC alone, or if the two polymers had been burned separately and their effluents mixed. In well-ventilated conditions, the LDPE/PVC mixture produced greater CO yields, about 1.5 times higher than for pure LDPE, and almost in the same range as for pure PVC. This could be explained by the presence of $\mathrm{HCl}$ in the fire effluent which interferes with the radical chain mechanism, preventing the conversion of $\mathrm{CO}$ to $\mathrm{CO}_{2}$ by the introduction of the stable chlorine radicals, which reacts with $\mathrm{OH} \cdot$ or $\mathrm{H} \cdot$ and results in high $\mathrm{CO}$ yield even for well-ventilated conditions. At very high temperatures $\left(950^{\circ} \mathrm{C}\right)$ the effect is reduced and both PVC and LDPE/PVC mixture show lower yields of $\mathrm{CO}$.

Similar behaviour is observed for the carbon monoxide evolution from the PA6 containing $20 \%$ brominated flame retardant. At 650 and $825{ }^{\circ} \mathrm{C}$, higher yields of carbon monoxide were observed than would be expected from the pure polymer, but at $950{ }^{\circ} \mathrm{C}$ the inhibition effect (and presumably the flame retardancy) disappears. This is particularly interesting because the presence of antimony is believed to produce antimony oxybromide $(\mathrm{SbOBr})$ which disproportionates into various species containing progressively less oxygen, ultimately resulting in antimony tribromide $\left(\mathrm{SbBr}_{3}\right)$. Therefore, instead of the active agent being $\mathrm{HBr}$, whose decomposition would release $\mathrm{H}$. radicals which could contribute to the replenishment of $\cdot \mathrm{OH}$ radicals to oxidise $\mathrm{CO}$ to $\mathrm{CO}_{2}$, the antimony-bromine species contain no hydrogen, but shows the same inhibiting effect on the main heat release process of combustion The high carbon monoxide yields for PS in well-ventilated conditions and the low carbon monoxide yields for PS in under- 
ventilated conditions, compared to other hydrocarbon polymers has been ascribed to the stability of the aromatic ring. This enhanced stability under well-ventilated conditions, leading to only partial oxidation is also strongly temperature dependent, with a noticeable reduction at $750{ }^{\circ} \mathrm{C}$, and a further reduction at 850 ${ }^{\circ} \mathrm{C}$. The different temperature sensitivity for PS and PVC suggests that additional carbon monoxide produced in well-ventilated conditions cannot be attributed solely to the aromatic decomposition products of PVC.

Overall, the implication for fire safety is that while halogens and aromatic structures may suppress ignition and reduce heat release in the early stages of fires, they probably have no significant effect once the fire grows and the temperature increases.

\section{REFERENCES}

[1] Fire Statistics United Kingdom 2007, Communities and Local Government, HMSO, 2009.

[2] Purser, D.A., "Toxicity Assessment of Combustion Products". SFPE Handbook of Fire Protection Engineering $\left(3^{r d} e d\right)$, National Fire Protection Association, Quincy, MA, 2002, p.2-83.

[3] Hull, T.R., Lebek, K., Pezzani, M., Messa, S., (2008) Comparison of toxic product yields of burning cables in bench and large-scale experiments. Fire Safety Journal 43: 140-150, http://dx.doi.org/10.1016/j.firesaf.2007.06.004

[4] Beyler, C.L., Hirschler, M.M., Thermal Decomposition of Polymers. National Institute of Standards and Technology, 2001, Chapter 7, Session 1, pp. 1-110-1-131.

[5] Cullis, C.F., Hirschler, M.M., The Combustion of Organic Polymers, Clarendon Press, Oxford, New York, Oxford University Press, 1981.

[6] Woolley, W.D., (1971) Decomposition Products of PVC for Studies of Fires, British Polymer Journal, 3(4), p. 186, http://dx.doi.org/10.1002/pi.4980030406

[7] Woolley, W.D., "Studies of the Dehydrochlorination of PVC in Nitrogen and Air," Building Research Establishment Current Paper CP 9/74, 1974.

[8] Purser, D.A., Stec, A.A., Hull. T.R., Effects of the Material and Fire Conditions on Toxic Product Yields, Fire Toxicity, Ed. A.A. Stec and T.R. Hull, Woodhead Publishing, Cambridge, 2010, Chapter 14, pp. 516-540.

[9] Purser, D.A., Fardell, P.J., Rowley, J., Vollam, S., and Bridgeman, B., (1994) An Improved Tube Furnace Method for the Generation and Measurement of Toxic Combustion Products Under a Wide Range of Fire Conditions, in Flame Retardants'94 Conference, London, Proceedings, Interscience Communications Ltd., London, p. 263.

[10] Hull, T.R., Stec, A.A. and Paul, K.T., 2009. Hydrogen Chloride in Fires. Fire Safety Science 9: 665-676, http://dx.doi.org/10.3801/IAFSS.FSS.9-665

[11] Hull, T.R., Lebek, K., Stec, A.A., Paul, K.T., Price, D., (2007) Bench-Scale Assessment of Fire Toxicity, Advances in the Flame Retardancy of Polymeric Materials: Current perspectives, FRPM'05 Ed. B. Schartel, Herstellung und Verlag, Norderstedt, 2007, pp.235-248.

[12] Purser, D.A., Performance of Fire Retardants in Relation to Toxicity, Toxic Hazard and Risk in Fires. Fire Retardant Materials, Ed. A.R. Horrocks and D. Price, CRC Press/Woodhead Publishing, Cambridge, UK, 2001, Chapter 12, pp 449-499.

[13] Pitts, W.M., (1995) "The Global Equivalence Ratio Concept and the Formation Mechanisms of Carbon-monoxide in Enclosure Fires," Progress in Energy and Combustion Science, 21, pp. 197237. http://dx.doi.org/10.1016/0360-1285(95)00004-2

[14] Hartzell, G. E., (2001) Engineering Analysis of Hazards to Life Safety in Fires: The Fire Effluent Toxicity Component, Safety Science, 38: 147-155, http://dx.doi.org/10.1016/S0925-7535(00)00065-5. 
[15] Ohlemiller, T.J., Smoldering Combustion. National Institute of Standards and Technology Internal Report (NISTIR), 1986.

[16] Hull, T.R., Paul, K.T., (2007) Bench-Scale Assessment of Combustion Toxicity - A Critical Analysis of Current Protocols, Fire Safety Journal, 42: 340-365 http://dx.doi.org/10.1016/j.firesaf.2006.12.006.

[17] Hull, T.R., Carman, J.M., Purser, D.A., (2000) Prediction of CO evolution from small-scale polymer fires, Polymer International, 49(10): 1259-1265, http://dx.doi.org/10.1002/10970126(200010)49:10<1259::AID-PI573>3.3.CO;2-4

[18] Schnipper, A., Smith-Hansen, L., Thomsen, S.E., (1995) Reduced Combustion Efficiency of Chlorinated Compounds, Resulting In Higher Yields of Carbon Monoxide, Fire and Materials, 19: 61-64, http://dx.doi.org/10.1002/fam.810190203

[19] Lebek, K., Hull, T.R., Price, D., (2005) Products of Burning Rigid PVC Burning Under Different Fire Conditions, Fire and Polymers: Materials and Concepts for Hazard Prevention, ACS Symposium Series No.922, Oxford University Press, pp.334-347.

[20] Stec, A.A., Hull, T.R., Torero, J.L., Carvel, R., Rein, G., Bourbigot, S., Samym, F., Camino, G., Fina, A., Nazare, S., Delichatsios, M., Effects of fire retardants and nanofillers on the fire toxicity Fire and Polymers V - Materials and Concepts for Fire Retardancy, Ch 21, 342-366, ACS Symposium Series 1013, Oxford University Press, (2009).

[21] Purser, D.A., Fardell, P.J., Rowley, J., Vollam, S., Bridgeman, B., Ness, E. M. (1994) Proceedings of the Flame Retardants '94 Conference, Interscience Communications, London.

[22] Lebek, K., Hull, T. R., Price, D., (2005). Fire and Polymers: Materials and Concepts for Hazard Prevention, ACS Symposium Series No.922, p344, Oxford University Press, Oxford.

[23] Hull, T.R. Stec, A.A. and Kaczorek, K., (2011) Fire Effluent Toxicity: Bench-Scale Generation of Toxic Products, Proceedings of the 6th International Seminar on Fire and Explosion Hazards, D Bradley (ed.), Leeds, UK.

[24] ISO/TS 19700: 2006, Controlled equivalence ratio method for the determination of hazardous components of fire effluents, 2006.

[25] Saso, Y. and Saito, N., 2000. Effects of Temperature, Aerodynamic Straining and Suppressant Concentration on Catalytic Inhibition $\mathrm{By} \mathrm{CF}_{3} \mathrm{Br}$ In Methane-air Counterflow Diffusion Flames. Fire Safety Science 6: 399-410, http://dx.doi.org/10.3801/IAFSS.FSS.6-399

[26] Saso, Y., Ogawa, Y., Saito, N., Wang, H., (1999) Binary $\mathrm{CF}_{3} \mathrm{Br}-$ and $\mathrm{CHF}_{3}$-inert flame suppressants: effect of temperature on the flame inhibition effectiveness of $\mathrm{CF}_{3} \mathrm{Br}$ and $\mathrm{CHF}_{3}$, Combustion and Flame, 118, 489-499, http://dx.doi.org/10.1016/S0010-2180(99)00012-7. 